\title{
THE COMMON CAUSES OF BLINDNESS IN NORTH WESTERN NIGERIA
}

\author{
BY \\ *IYAMU E AND AHMED M.T. \\ DEPARTMENT OF OPTOMETRY, \\ UNIVERSITY OF BENIN, BENIN-CITY, NIGERIA. \\ Email: eghosaiyamn@yahoo.com \\ *Corresponding author
}

\begin{abstract}
The purpose of this study was to find the common causes of blindness in North-Western Nigeria. A total of 475 cases were carefully selected using World Health Organization (WHO) categorization criteria. These cases were divided into five groups: 0-20, 21-41, 41-60, 61-80 and above 80 years. From the study, the following causes of blindness were identified: cataract (51.4\%), glaucoma (10.7\%) corneal disease (9.5\%), trauma (6.7\%), staphyloma (3.6\%) and refractive error $(1.5 \%)$. Blindness is a significant burden to society in that the cost of lost of productivity and of rehabilitation and education of the blind is very high and increasing. The emphasis on Vision 2020 therefore, is controlling the leading causes of blindness with a view to eliminating them.
\end{abstract}

KEYWORDS: Prevention, Blindness, Legal blindness, Low vision, Low vision aids.

\section{INTRODUCTION}

Blindness is defined as corrected visual acuity in the better eye of less than $3 / 60$ (finger counting at $3 \mathrm{~m}$ ), with or without light perception and/or central visual field of less than $10^{10}$. Legal blindness can mean tunnel vision, no central vision, cloudy or extremely blurred vision, seeing just shadows or no shadows at all.

Blindness is a major health problem that has received relatively little attention in world wide effort's to promote health. The vast majority of World's blind live in developing countries where infections, malnutrition and lack of eye care give rise to a high proportion of blindness, particularly in rural population of blindness, particularly in rural populations in contrast to industrialized countries, where blindness is due mainly to degenerative and metabolic disorders related to ageing $^{2}$.

It was estimated that there are at least 38 million blind people in the World and 110 million people with low vision, that is, corrected visual acuity of less than 6/18(0.3) as at $1997^{2}$. Blindness caused by infections or nutritional deprivation can easily be prevented and visual loss from cataract can be restored by simple surgery. Malnutrition resulting in Vitamin A deficiency can cause permanent blindness by damaging the cornea. This is particularly true in children living under conditions of general malnutrition that are affected by superimposed diseases such as measles and diarrhea that can aggravate their Vitamin A status ${ }^{2}$.
Another cause of blindness is Onchocerciasis (River blindness) in areas where there are fast flowing streams in which black flies responsible for the transmission of the parasites, Onchocerca volvulus are prominent. Glaucoma, which is characterized by consistently high intraocular pressure (IOP) of the eyes results in visual impairment. It accounts for $15 \%$ of all blindness. The most common types is primary open angle glaucoma (POAG). Other causes of blindness are trachoma (Overcrowding and poor hygiene enhance the spread of the infection) and trauma.

$\mathrm{Kragha}^{3}$, in his study showed the major causes of blindness in Northern Nigeria as cataract (45.6\%), glaucoma $(19.0 \%)$, corneal diseases $(8.9 \%)$, trachoma $(5.5 \%)$ and trauma $(4.7 \%)$.

A large percentage of blindness in developing countries can either be cured or could have been prevented by reasonable deployment of skills and resources. This is termed avoidable blindness. The general lack of eye care services in underserved communities in developing countries is responsible for much blindness. Early treatment of infections and nutritional eye diseases is essential to prevent visual loss. ${ }^{2}$

Low vision, partial sight or subnormal vision may be defined as reduced central acuity or visual field loss, which even with the best optical correction provided by regular lenses still results in visual impairment from a performance stand point ${ }^{4}$. David $(1980)^{5}$, pointed out that low vision can be improved by sharpening the retinal image 
(for example, conventional spectacles for ametropia, contact lenses or pinhole for irregular astigmatism), improving its contrasts (for example illumination control) or making it larger (for example, magnification), usually all these factors are combined. Low vision aids (LVAs) are special devices used by persons whose vision cannot be improved by conventional spectacles. Age-related macular degeneration (ARMD), diabetic maculopathy, heredomacular degeneration and pathological myopia require LVAs. Other disorders that may benefit from LVAs are retinitis pigmentosa, partial optic atrophy and some cases of advanced glaucoma and early cataract. Some non-progressive conditions like albinism, aniridia, microphthalmos, post-traumatic corneal scars, failed corneal graft, failed retinal detachment surgery and macular scars may also benefit from LVAs $^{6}$.

\section{METHOD}

Clinic records were obtained from the Hospital records of in- and out-patients seen in the Eye Clinic of Usman Danfodiyo University Teaching Hospital (UDUTH). This hospital was established to serve the Northwestern zone of the country consisting of Sokoto, Zamfara, Kebbi and Katsina States. A total of 475 cases were selected from the pool of 3,975 cases seen within the period of 10 years, that is, 1992-2001. The age of the patient was at the time of attendance. Sampling of the blind was based on WHO's categorization criteria for blindness ${ }^{3}$. The sample was distributed into 5 groups which are: $0-20,21-40,41-60,61-80$ and above 80 years.

\section{RESULT}

The blind cases in the 41-60 years age group had the highest percentage (31\%) as shown in table 1 . This group served as the mid-point between the young and the old groups. This represented the ripe productive group. For the same group, the males had a higher percentage $(41.3 \%)$ than females (14.6\%), the males being four times the number of clinically blind females (tables 2). The common causes of blindness in North-western Nigeria were shown in table 3. The sex distribution of the causes of blindness was also found in the table. Cataract constituted the major cause of blindness $(51.4 \%)$ for the sample, and this was followed by POAG $(10.7 \%)$. Blindness due to refractive error (degenerative myopia) recorded the least percentage $(1.9 \%)$. Retinoblastoma and staphyloma accounted for $3.6 \%$ each.

\section{DISCUSSION}

Blindness is a significant burden to society in that the cost of lost of productivity and of rehabilitation and education of the blind is very high and increasing. The swift and effective use of resources for the prevention of blindness will provide enormous savings in both money and human suffering ${ }^{2}$. From this study, cataract was $244(51.4 \%)$. All the causes of the cataract could not be ascertained from the records. However, a few were due to trauma and congenital factors. Others may have been due to advancing age and hereditary factors. Glaucoma was the next in hierarchy of causes of blindness. POAG was recognized as the main type of glaucoma. This was responsible for $10.7 \%$ of the causes of blindness. Klopfer and Paikowsky $^{7}$ reported a higher prevalence of POAG, which was 4.7 times that of the whites, for blacks in their study. This means that blacks of African descents are at greater risk of developing POAG than their white counterparts. The findings of this study are comparable to those of some investigators who identified cataract, POAG and ARMD as leading causes of blindness in United State of America ${ }^{8-10}$.

With early detection of POAG and appropriate management using drugs and /or surgical approach (trabeculectomy), some degree of vision can be preserved if not significantly restored. Corneal diseases accounted for 45 cases $(9.5 \%)$. Majority of this was due to Vitamin A deficiency, which resulted in xerophthalmia and xerosis with consequent scarring of the cornea. Trauma accounted for 32 cases $(6.7 \%)$ and by identifying the possible agents and keeping away from them can prevent conditions that would lead to blindness.

The control of blindness in children is a priority within WHO's Vision 2020 programme. Strategies need to be region specific, based on activities to prevent blindness in the community through immunization against measles, health education and control of Vitamin A deficiency and provision of tertiary level eye care facilities for conditions that require specialist manaagment ${ }^{11}$.

As part of promoting eye health in children and adults in Nigeria, the National agency for food and drug administration and control (NAFDAC) recently mandated all manufacturers of sugar to fortify such with Vitamin A. This is with a view to eliminating blindness caused by vitamin A deficiency especially in children since they are the major consumers of sugar. Although the blindness due to refractive error was about $2 \%$ of total blind 
cases, high degenerative myopia can result in retinal detachment with attendant vision loss. But when such condition is suspected early, with appropriate intervention of correcting the error with the right device, vision loss could be prevented.

The role the Optometrist in prevention of blindness must be community based if WHO's Vision 2020 programme ï The Right to Sight İ Global initiative for the elimination of avidable blindness must be achieved. WHO and WCO recently reached a working agreement on the role of the Optometrist in Vision 2020. All cases of refraction and low vision are to be handled by Optometrists towards realization of the goals of Vision 2020. The emphasis of the programme is on controlling the leading causes of blindness like uncorrected refractive error, cataract, trachoma, onchocerciasis and childhood blindness. Eighty percent of global blindness is avoidable and could be prevented or cured through cost-effective means ${ }^{2}$.

TABLE 1: DISTRIBUTION OF BLINDNESS BYAGE GROUP

\begin{tabular}{|c|c|c|}
\hline Age group (yrs) & Percentage \% & Total Number (475) \\
\hline $0-20$ & 22.5 & 107 \\
\hline $21-40$ & 21.3 & 101 \\
\hline $41-60$ & 30.1 & 143 \\
\hline $61-80$ & 20.6 & 98 \\
\hline Above 80 & 5.4 & 26 \\
\hline
\end{tabular}

TABLE 2: SEX DISTIBUTION OF BLINDNESS

\begin{tabular}{|c|c|c|c|c|}
\hline Age group (yrs) & $\begin{array}{l}\text { Total No. of Males } \\
\text { (276) }\end{array}$ & $\begin{array}{l}\text { \%otal No. of } \\
\text { Females (199) }\end{array}$ & \% \\
\hline $0-20$ & 69 & 25.0 & 38 & 19.1 \\
\hline $21-40$ & 40 & 14.5 & 61 & 30.7 \\
\hline $41-60$ & 114 & 41.3 & 29 & 14.6 \\
\hline $61-80$ & 49 & 17.8 & 49 & 24.6 \\
\hline Above 80 & 4 & 1.4 & 22 & 11.0 \\
\hline
\end{tabular}

TABLE 3: CAUSE OF BLINDNESS IN NORTH WESTERN NIGERIA

\begin{tabular}{|l|l|l|l|}
\hline Diseases/Causes & $\begin{array}{l}\text { Total of Blindness } \mathrm{n}=475 \\
(\%)\end{array}$ & $\begin{array}{l}\text { Males } \\
\mathrm{n}=277(\%)\end{array}$ & $\begin{array}{l}\text { Females } \\
\mathrm{n}=198(\%)\end{array}$ \\
\hline Cataract & $244(51.4)$ & $149(53.8)$ & $95(53.4)$ \\
\hline Glaucoma & $51(10.7)$ & $25(9.0)$ & $26(14.6)$ \\
\hline Corneal & $45(9.5)$ & $20(7.2)$ & $25(14.0)$ \\
\hline Trachoma & $12(2.5)$ & $4(1.4)$ & $8(4.5)$ \\
\hline Refractive error & $9(1.9)$ & $8(2.9)$ & $1(0.6)$ \\
\hline Retinoblastoma & $17(3.6)$ & $11(4.0)$ & $5(2.8)$ \\
\hline ARMD & $12(2.5)$ & $8(2.9)$ & $4(2.2)$ \\
\hline Trauma & $32(6.7)$ & $20(7.2)$ & $12(4.3)$ \\
\hline Staphyloma & $17(3.6)$ & $12(4.3)$ & $5(2.8)$ \\
\hline Cellulitis & $15(3.2)$ & $13(4.7)$ & $2(1.2)$ \\
\hline Others & $22(4.6)$ & $7(2.5)$ & $15(8.4)$ \\
\hline
\end{tabular}




\section{R E F E R E N C E S}

1. International statistical classification of diseases and related health problems (1992): Tenth Rev. Geneva, World Health Organization.

2. WHO (1997): Strategies for prevention of blindness in National programmes: A primary health care approach, $2^{\text {nd }}$ Edn. England, $101 \mathrm{pp}$.

3. Kragha, I. (1987): Causes of Blindness in Northern Nigeria. Am. J. Optom. Physiol. Opt, 64(9):708-10.

4. Mehr, E. B. and Freid, A. N. (1975): Low vision care. Professional Press Inc. Chicago, Illinois, 254pp.

5. Davis, M. (1980): Optics and refraction- a Clinical approach., $2^{\text {nd }}$ Edn. St Louis, pp 61031.

6. Datt, L. C. (2000): Modern Ophthalmology. $2^{\text {nd }}$ Edn. Delhi Jaypee Brothers, 1049pp.

7. Klopfer, J. and Paikowsky S. J. (1993): Epidemiology and clinical impact of Glaucoma. Appleton \& Lange, Connecticut,

\section{4pp.}

8. Tielsch, J. M., Sommer, A. and Katz, J. (1990): Blindness and Visual impairment in an American urban population: The Baltimore Eye Survey. Arch. Ophthalmol, 108: 286-90.

9. Tielsch, J. M., Sommer, A. and Katz, J. (1991): Racial variation in the prevalence of Primary open angle glaucoma: The Baltimore Eye survey. JAMA, 266 (3):369-74.

10. Leibonitz, H. M., Krueger, D. E. and Maunder, L. R. (1980): The Framingham Eye study Monograph: An Ophthalmological and epidemiological study of cataract, glaucoma, diabetic retinopathy, macular degeneration and visual acuity in a general population of 2,631 adults, 1973-1975. Surv Ophthalmol, 24 (Suppl): 335-610.

11. Gilbert, C. and Foster, A. (2001): Childhood blindness in the context of vision 2020: The right to sight. Bull. World Health Organization, 79(3): 227-32. 